\title{
Information management and reading habits of German diabetologists: a questionnaire survey
}

\author{
S. Trelle \\ Research Unit of Biotechnology, Society, and Environment Research Group of Medicine, University of Hamburg, \\ Hamburg, Germany
}

\begin{abstract}
Aims/hypothesis. Journals play an important part in continuing medical education and in influencing the prescription of drugs. Because little is known about reading habits and information management of specialists a questionnaire survey among German diabetologists was conducted.

Subjects and methods. A non-randomised sample of 461 German diabetologists was selected from a database of German diabetologists $(n=1585)$. A questionnaire was developed (92 items) which consisted of eight sections: continuing education in general, decision making and problem solving, use of databases, reading habits, knowledge of technical terms and critical appraisal skills, personal data.

Results. The adjusted response rate was $57 \%$ (crude $52 \%)$. Most influential factors for therapeutic decision making were due to own experience, continuing education events, published material, and colleagues. The influence of industry related factors was perceived low. A relatively high rate of respondents (39\%) perceived the influence by patients as rather low. Overall
\end{abstract}

90\% had convenient access to the internet, MedLine or EMBASE but only $45 \%$ searched databases regularly (three searches per month). Median time for reading journals was $3 \mathrm{~h}$ a week. Five journals were read regularly, $25 \%$ of which were diabetological journals and $47 \%$ of the respondents did not read English written journals regularly. The methods section of an article was seldom read whereas the abstract and the discussion were almost always read. Most respondents had some understanding of technical terms but reported practices of appraising articles were inadequate.

Conclusion/interpretation. It could be shown that reading expenditures and critical appraisal skills of diabetologists are slightly higher compared with nonspecialists. But the concept of evidence-based medicine still does not seem to be incorporated in clinical practice. [Diabetologia (2002) 45:764-774]

Keywords Clinical medicine, continuing medical education, decision making, diabetologists, evidencebased medicine, information management, periodicals, physicians, questionnaires, reading habits.
Journals play a major part in continuing medical education (CME) of physicians [1, 2, 3]. They are rela-

Received: 6 August 2001 / Revised: 15 January 2002

Published online: 9 May 2002

(C) Springer-Verlag 2002

Corresponding author: Dr. S. Trelle, Research Unit Biotechnology, Society and Environment Research Group of Medicine, University of Hamburg, Falkenried 94, D-20251 Hamburg, Germany, e-mail: trelle@uni-hamburg.de

Abbreviations: CME, Continuing medical education; IQR, interquartile range tively inexpensive, convenient to handle, and they are viewed as one of the best information sources for identifying innovative technologies [4]. But the influence of reading journal articles on clinical decision making is not clear $[5,6,7,8,9,10]$. This could be due to the perception that clinical research is not appropriate enough [11], critical appraisal skills are not sufficient, or there could be other problems with interpreting medical articles $[12,13,14,15,16]$. Moreover, opinion leaders suspect that physicians obtain information about drug therapy mainly from the pharmaceutical industry and not from peer-reviewed jour- 
nals. They assume that physicians often base their therapeutic decisions on promotional material and on the opinion of colleagues and that this problem is particularly predominant in Germany compared to the United Kingdom or the United States [17, 18]. This debate was stimulated by the evidence-based medicine movement and is reflected in the ongoing discussion about quality assurance, mandatory continuing medical education and by the efforts made to promote evidence-based medicine $[19,20]$.

Some studies evaluated the habits of continuing medical education, information management, reading, and attitudes towards evidence-based medicine [2, 3, $21,22,23,24,25,26,27,28]$. Most of these studies are based on general practitioners or general internists. Therefore little is known about specialists. As this holds true for diabetologists an explorative survey was conducted among German diabetologists. Furthermore this survey was intended to provide the more anecdotal assumptions and the on-going discussions with some facts.

\section{Subjects and methods}

Questionnaire. A questionnaire was developed considering three already published surveys [23, 27, 29]. It consisted of eight sections and comprised 92 items of which three were asked openly. The questions relevant for this article covered the following fields (Appendix): therapeutic decision making, information about innovative drugs, database handling, reading habits, importance of journals in connection with innovative drugs, methods of evaluating journal articles (applying a question published previously [23]), knowledge of technical terms (applying a question published previously [27]), personal data, and comprehensibility of the questionnaire.

Regarding the question about the knowledge of technical terms the previously published question was modified according to the terms and the response-categories [27]. In addition, the knowledge of a fictitious term (McNemar Quality Scale) was tested to evaluate socially desired responses. From the responses to the remaining 12 terms a knowledge score was calculated: every affirmative answer to the category "I understand this term and could explain it to others" was valued with one point, to the category "I have some understanding" was valued with a half point. The sum total was rounded and the maximum score was 12 points. Readiness to learn was also calculated: the number of affirmative answers to the category "do not know this term but would like to understand" was divided by the sum of this category and of the category "do not know". Eventually there was a question on the importance of these terms in daily clinical work.

Sample. The sample comprised 461 diabetologists in the northern part of Germany and was selected from a database of German diabetologists (Diabetologen, DDG; http://www.diabetesweb.de) because the German Diabetes Association (DDG) could not provide data directly. It represented $29 \%$ of all 1585 diabetologists in the database. For technical reasons it was not possible to draw a random sample; therefore, the sample was selected by the first figure of the zip code (codes 1-3; this area covers 10 different states and includes the biggest cities as well as rural parts of Germany). Sample size was calcu- lated with regard to confidence intervals for frequencies: a $95 \%$ CI of $10 \%-15 \%$ for questions answerable dichotomously was considered narrow enough. This required a sample size of about 200 persons. Response rates of prior surveys ranged from $50 \%$ to $70 \%$.

In October 2000 the questionnaire was distributed for the first time. One week later a reminder was sent to all participants and after 3 weeks another questionnaire was sent to all non-respondents. A cover letter was enclosed with a stamped self-addressed envelope. Coding by numbers for response control was explicitly mentioned but the analysis was fully anonymous.

Statistical analyses. Descriptive statistics were mainly used. The chi-square test was used for comparisons of categorical data (Yates continuity corrected for comparisons with one degree of freedom). Two-sided $p$ values of less than 0.05 were considered significant. Analyses were done with EpiInfo 2000, version 1.0.4 and KyPlot, version 2.0.

\section{Results}

Of the 461 questionnaires distributed, 45 (10\%) were returned because they were undeliverable. In this group the proportion of hospital-based physicians was higher (33/45: $73 \%$ vs 199/416: $48 \% ; \chi^{2}=9.564$; $p=0.002$ ) and the proportion of practising physicians was lower $\left(9 / 45: 20 \%\right.$ vs $187 / 416: 45 \% ; \chi^{2}=9.349$; $p=0.002$ ) than in the remaining sample. Other differences have not been found.

There were 239 questionnaires eligible for analysis, resulting in a crude response rate of $52 \%$ and an adjusted response rate of $57 \%$. The characteristics of the respondents, all German diabetologists (Diabetologen DDG), and the whole sample were compared (Table 1) as well as all the respondents and nonrespondents (Table 2).

Of the respondents $24 \%(56 / 235)$ stated that the questions were easy to understand, 68\% (160/239) found them rather easy to understand, and $8 \%$ (19/235) found them rather difficult. Nobody found the questions difficult to understand. Comments on the survey were very different and ranged from "such questionnaires are impertinent" to "very good survey on an important issue, and possibly I will reconsider my continuing medical education habits" (positive and negative comments were roughly balanced).

Therapeutic decision making. Own experience, published material, as well as recommendations from colleagues were most important for the therapeutic decision making of the respondents (Fig. 1). A remarkable $39 \%(92 / 238)$ of the respondents reported that patients had a rather small to no influence on therapeutic decisions. By a wide margin the most important sources to hear about innovations were CME events (146/236: $62 \%)$, published clinical trials (145/236: 61\%), and pharmaceutical representatives (136/236: 58\%). Other 
Table 1. Characteristics of respondents, sample, and all German diabetologists

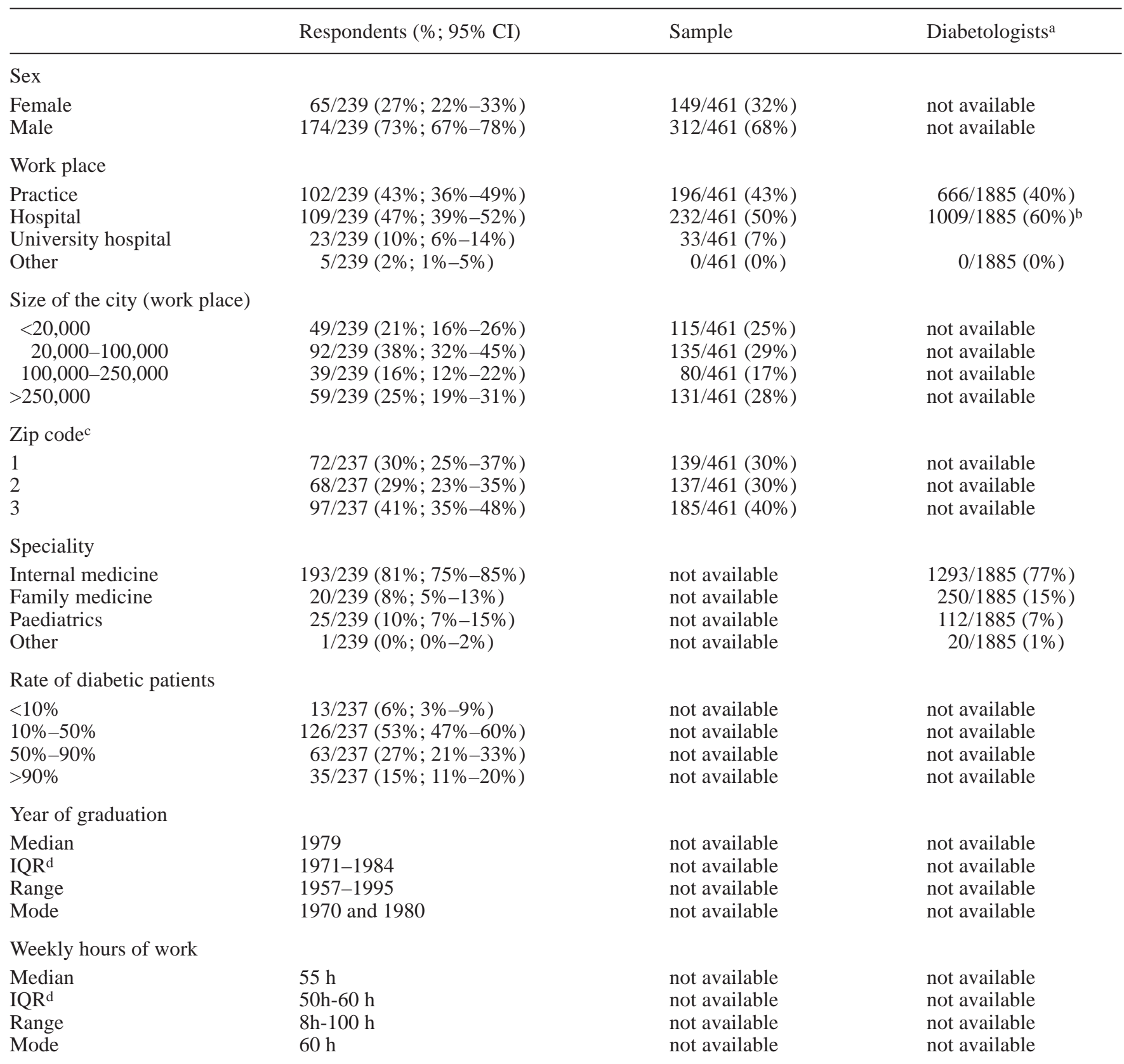

a Data from Willms (2000): Ausschuß Diabetologe DDG: Jahresbericht 1999. URL: http://www.deutsche-diabetesgesellschaft.de/frames/frame2.htm (Accessed 10/9/2000)

sources were narrative reviews (65/236: $28 \%)$, literature from the industry (55/236: $23 \%$ ), and advertisements (54/236: 23\%). All remaining sources were only of minor importance (colleagues 25/236: 11\%; quality circles: 24/236: $10 \%$; systematic reviews: 21/239: 9\%; books and published guidelines: 5/236: 2\%; patients: $3 / 236: 1 \%$ ).

Use of databases. Of the respondents 45\% (107/238) reported that they used databases regularly. The median number of database searches a month was

\footnotetext{
$\mathrm{b}$ Hospital and university hospital combined

${ }^{c}$ Two questionnaires returned without code number

d IQR, interquartile range
}

three [interquartile range (IQR): 2-5; range: 1-55; mode: 1]. Of the respondents $88 \%$ (88/107) did searches until they had satisfying results, $9 \%(10 / 107)$ spent more than $45 \mathrm{~min}, 7 \%(8 / 107)$ between 15 and $45 \mathrm{~min}$ and one respondent spent under $15 \mathrm{~min}$ per search. The most important reason not to conduct database searches was the effort involved (97/120: $81 \%$ ). This was followed by a limited knowledge of how to handle a database (72/120: $60 \%)$. Only a minority thought that the results of such searches were dissatisfying (28/120: 23\%). All reasons reported in 


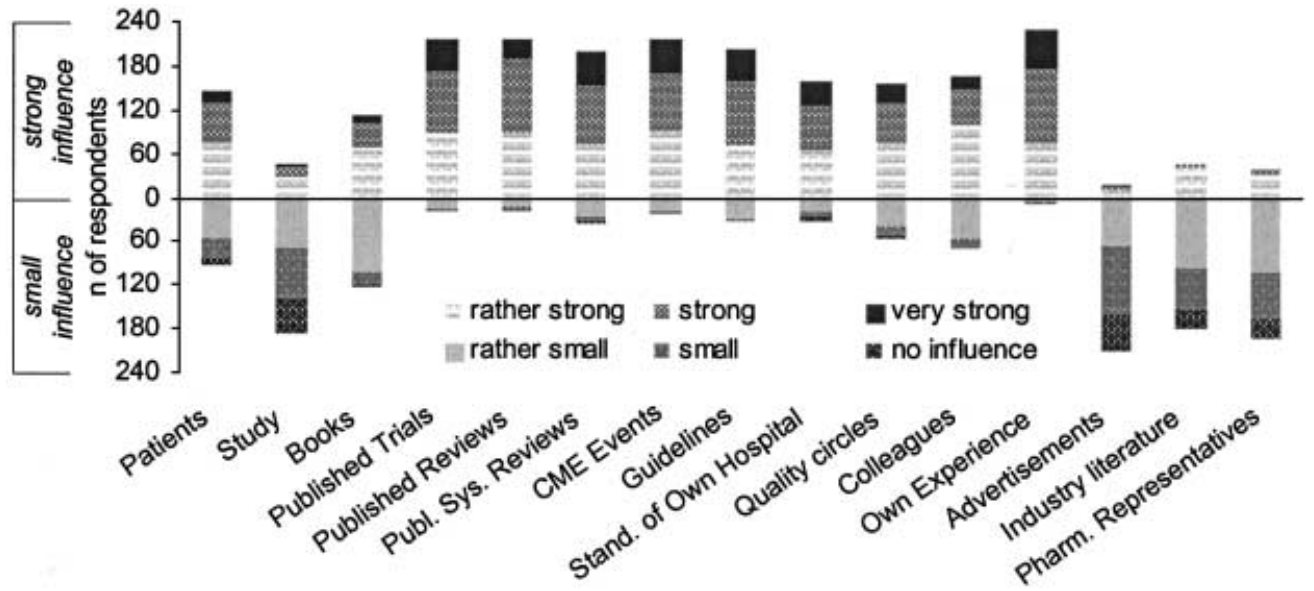

Fig. 1. Self perceived influence of various factors on therapeutic decision making. Crosses at category 'Do not use' were disregarded

Table 2. Characteristics of respondents and non-respondents

\begin{tabular}{lrrr}
\hline & Respondents & Non-respondents & $\chi^{2}$ \\
\hline Sex & & & \\
Women & $65 / 239(27 \%)$ & $84 / 222(38 \%)$ & 5.481 \\
Men & $174 / 239(73 \%)$ & $138 / 222(62 \%)$ & \\
Work place & & & \\
Practice & $102 / 239(43 \%)$ & $94 / 222(42 \%)$ & \\
Hospital & $109 / 239(47 \%)$ & $123 / 222(55 \%)$ & \\
University hospital & $23 / 239(10 \%)$ & $10 / 222(5 \%)$ & \\
Other & $5 / 239(2 \%)$ & $0 / 222(0 \%)$ & \\
Size of the city (work place) & & & \\
$\quad<20,000$ & $49 / 239(21 \%)$ & $66 / 222(30 \%)$ & \\
$\quad 20,000-100,000$ & $92 / 239(38 \%)$ & $43 / 222(19 \%)$ & \\
$100,000-250,000$ & $39 / 239(16 \%)$ & $41 / 222(18 \%)$ & \\
$>250,000$ & $59 / 239(25 \%)$ & $72 / 222(32 \%)$ & \\
Zip code & & & \\
1 & & & \\
2 & $72 / 237(30 \%)$ & $67 / 222(30 \%)$ & \\
3 & $68 / 237(29 \%)$ & $69 / 222(31 \%)$ & \\
\hline
\end{tabular}

a Two questionnaires returned without code number

the answers to the open question fell into these categories as well. Overall 44\% (98/225) of respondents had access to the world wide web, MedLine or EMBASE on their ward or surgery, $16 \%(35 / 225)$ had it in their hospital, and 31\% (70/225) at home. Only $10 \%(22 / 225)$ had to go to a medical library (e.g. at a university hospital) for such an access. The relation between access and conduct of database searches was not conclusive.

Reading habits. The median time for reading was $3 \mathrm{~h}$ a week for journals (IQR: 2-5; range: 0-16; mode: 2) and $1 \mathrm{~h}$ (IQR: 1-1; range: 0-7; mode: 1) for books. The median number of journals that were read regularly was five (IQR: 4-7; range: 0-15; mode: 4)
$25 \%$ of which were diabetological journals (IQR: 20\%-40\%; range: $0 \%-100 \%$; mode: $25 \%$ ), and $13 \%$ were journals written in English (IQR: 0\%-33\%; range: $0 \%-83 \%$; mode $0 \%$ ). On average respondents read one diabetological journal [most important "Diabetes und Stoffwechsel" - the official journal of the German Diabetes Association (232/239: 97\%) and "Experimental and Clinical Endocrinology and Diabetes" (68/239: 29\%)] and 47\% (111/238) of respondents did not read English written journals regularly. A majority of respondents who read journals in English read one to two of these [most important "The New England Journal of Medicine" (80/239: 34\%) and "Experimental and Clinical Endocrinology and Diabetes" (68/239: 29\%)]. 
Table 3. How diabetologists appraise the scientific validity of a research article

\begin{tabular}{|c|c|c|c|c|}
\hline & Always & Often & Seldom & Never \\
\hline Compare with own experience $(n=230)$ & $82(36 \%)$ & $119(52 \%)$ & $27(12 \%)$ & $2(1 \%)$ \\
\hline Rely on editors/peer review process $(n=225)$ & $4(2 \%)$ & $104(46 \%)$ & $99(44 \%)$ & $18(8 \%)$ \\
\hline Contact authors' $(n=223)$ & $0(0 \%)$ & $3(1 \%)$ & $82(37 \%)$ & $138(62 \%)$ \\
\hline Examine methods section $(n=226)$ & $15(7 \%)$ & $70(31 \%)$ & $89(39 \%)$ & $52(23 \%)$ \\
\hline Discuss with colleagues $(n=227)$ & $15(7 \%)$ & $150(66 \%)$ & $59(26 \%)$ & $3(1 \%)$ \\
\hline
\end{tabular}

Table 4. Knowledge of technical terms

\begin{tabular}{|c|c|c|c|c|c|}
\hline & $\begin{array}{l}\text { Understand and } \\
\text { could explain to } \\
\text { others }\end{array}$ & $\begin{array}{l}\text { Some } \\
\text { understanding }\end{array}$ & $\begin{array}{l}\text { Knowledge } \\
\text { but no } \\
\text { understanding }\end{array}$ & $\begin{array}{l}\text { Do not know } \\
\text { but would } \\
\text { like to }\end{array}$ & $\begin{array}{l}\text { Do not } \\
\text { know }\end{array}$ \\
\hline Systematic Review ( $n=233$ ) & $113(49 \%)$ & $94(40 \%)$ & $9(4 \%)$ & $9(4 \%)$ & $8(3 \%)$ \\
\hline Meta-Analysis $(n=235)$ & $158(67 \%)$ & $61(26 \%)$ & $6(3 \%)$ & $7(3 \%)$ & $3(1 \%)$ \\
\hline Publication bias $(n=235)$ & $46(20 \%)$ & $51(22 \%)$ & $34(15 \%)$ & $43(18 \%)$ & $61(26 \%)$ \\
\hline Relative risk reduction $(n=233)$ & $104(45 \%)$ & $77(33 \%)$ & $12(5 \%)$ & $25(11 \%)$ & $15(6 \%)$ \\
\hline Absolute risk reduction $(n=234)$ & $104(44 \%)$ & $81(35 \%)$ & $13(6 \%)$ & $21(9 \%)$ & $15(6 \%)$ \\
\hline Number needed to treat $(n=235)$ & $128(55 \%)$ & $55(23 \%)$ & $7(3 \%)$ & $15(6 \%)$ & $30(13 \%)$ \\
\hline Intention-to-treat analysis $(n=234)$ & $101(43 \%)$ & $62(27 \%)$ & $18(8 \%)$ & $22(9 \%)$ & $31(13 \%)$ \\
\hline Confidence interval $(n=231)$ & $61(26 \%)$ & $63(27 \%)$ & $36(16 \%)$ & $25(11 \%)$ & $46(20 \%)$ \\
\hline Alpha error (Type-I-Error) $(n=233)$ & $33(14 \%)$ & $49(21 \%)$ & $34(15 \%)$ & $44(19 \%)$ & $73(31 \%)$ \\
\hline Beta error (Type-II-Error) $(n=233)$ & $34(15 \%)$ & $47(20 \%)$ & $34(15 \%)$ & $45(19 \%)$ & $73(31 \%)$ \\
\hline Positive predictive value $(n=233)$ & $69(30 \%)$ & $91(39 \%)$ & $27(12 \%)$ & $26(11 \%)$ & $20(9 \%)$ \\
\hline Odds ratio $(n=234)$ & $67(29 \%)$ & $79(34 \%)$ & $24(10 \%)$ & $19(8 \%)$ & $45(19 \%)$ \\
\hline McNemar-Quality-Scale $(n=234)$ & $1(0 \%)$ & $16(7 \%)$ & $24(10 \%)$ & $76(33 \%)$ & $117(50 \%)$ \\
\hline
\end{tabular}

When respondents read a scientific article only $2 \%(4 / 176)$ always read its methods section, $34 \%$ (60/176) read it often, 57\% (100/176) seldom, and 7\% $(12 / 176)$ never. In contrast the abstract was read almost always (140/182: $77 \%$ always; $42 / 182$ : $23 \%$ often) as well as the discussion (72/179: 40\% always; 92/179: $51 \%$ often; 15/179: $8 \%$ seldom).

Critical appraisal and knowledge of technical terms. How the respondents evaluated the scientific validity of a research article related to a clinical problem was recorded (Table 3 ). Only a minority evaluated it by examining methods. An overwhelming majority compared the results with their own experience to appraise its scientific validity.

Median knowledge-score of technical terms was six (IQR: 4-8; range: 0-12; mode: 6). Most problematic terms were the two errors related to hypothesis testing (Table 4). On average about one third of the respondents stated that they could explain the meaning of respective terms to others. Remarkably, the term 'MetaAnalysis' was allegedly understood much better than the term 'Systematic Review' and the term 'Number Needed to Treat (NNT)' was also understood much better than 'Absolute Risk Reduction (ARR)'. 7\% (17/234) reported that they knew the fictitious term.
Readiness to learn was balanced between the two extremes: $37 \%(75 / 205)$ of respondents had no interest in learning (readiness to learn $=0$ ) whereas $33 \%(67 / 205)$ had a great interest (readiness to learn $=1,0$; i.e. they would like to understand every unknown term). Consistent with these findings, respondents attributed different importance to these terms in daily clinical practice: $10 \%(23 / 233)$ judged them as very important, 44\% (102/233) rather important, 34\% (79/233) rather unimportant, and $12 \%(29 / 233)$ as unimportant.

Importance of journals. Journals were judged by $26 \%$ $(62 / 235)$ as very important for prescribing a new drug, $64 \%(150 / 235)$ found them rather important, and only $10 \%(23 / 235)$ considered them as rather unimportant. Only $41 \%(97 / 236)$ of respondents stated that the information provided by journals is sufficient enough to prescribe a new drug for the first time.

\section{Discussion}

Methodological issues. Because the selection of the sample was not randomised, systematic biases are possible. As the available demographic characteristics of all German diabetologists were limited, an assess- 
ment of the representativity of the sample is restricted. Differences in the rates of speciality can be considered as biased (Table 1) but as a relationship between speciality and specific responses has not been found (checked for eight items; data not shown) it is not clear if this is relevant for the results of the survey. Although the response rate lies below the average of other surveys [30,31] no major differences in the four available demographic characteristics could be detected between the respondents and the sample (Table 1). The relatively higher rate of undeliverable questionnaires among hospital-based physicians is certainly negligible since the number of persons was too small. Non-response bias is another problem as indicated by the differences between the respondents and nonrespondents (Table 2) but its relevance seems also questionable because associations between specific responses and sex, work place, or location of work place were not conclusive (checked for eight items; data not shown). Nevertheless these facts suggest that caution should be used when generalising the results.

Certain limitations lie in the methodology of surveys themselves. This sort of study is susceptible to a series of biases and inaccuracies if conclusions about the actual habits of respondents are drawn [32, 33]. Literature about response biases of physicians is limited and inconclusive [34, 35, 36, 37] and studies about inaccuracies in surveys of CME habits do not exist yet. At present about $10 \%$ of responses seem inaccurate. This can be estimated at the rate of respondents who knew the McNemar-Quality-Scale and the higher rate $(11 \%)$ of respondents who could explain the term 'Number Needed to Treat' in comparison with 'Absolute Risk Reduction'. Therefore all rates or numbers in surveys should be interpreted as trends rather than at face value.

Interpretation of findings. Despite these limitations this study can add substantial information on reading habits and information management of diabetologists.

Therapeutic decision making. The large number of factors which were perceived important in guiding therapeutic decisions confirms previous studies on decision making. These studies showed that therapeutic decision making can not be explained by simple models but is a consequence of complex interactions of different factors [38]. The importance of industry related factors might be underestimated because previous studies showed that physicians often underestimated their influence [39]. The high rate of respondents who do not involve patients in their therapeutic decisions is remarkable but seems realistic [40]. Further efforts are needed to promote shared (and informed) decision making because involvement of patients is not only an ethical obligation but also required for an optimal treatment and the compliance of patients [41, 42, 43, 44, 45].
Use of databases. Although $90 \%$ of respondents had a relatively convenient access to medical databases, only $45 \%$ use them regularly, comparable to another study [46]. However, effort was reported to be the most important barrier for not conducting database searches. This suggests that other inconveniences are prevailing (e.g. databases might not be user-friendly enough). Developments like the "Clinical Queries" by the National Library of Medicine (http://www.ncbi. nlm.nih.gov:80/entrez/query/static/clinical.html) might help to overcome these problems. Still, they do not seem to be convenient enough because database users do searches only about three times a month though "information needs arise regularly when doctors see patients" [47] and these needs can be met to a relevant proportion by the literature $[48,49]$. Besides the problem of handling a database, the relatively low rate of journals read in English could indicate that language barriers are another reason [50].

Reading habits. The time spent on reading journals is comparable with the results of previous studies but the number of journals read regularly was $25 \%$ to $30 \%$ higher among German diabetologists [24, 25, 28, 29, 51]. The rate of physicians who read journals in English seems low but it is also comparable to a previous study among general internists [29]. As most of the important advances in medicine are reported in journals written in English [52, 53], efforts should be made to increase this rate - either by translating English language publications or by promoting and offering language courses (preferably to medical students at the beginning of their undergraduate studies already).

As the accuracy and sufficiency of abstracts [54, 55] and discussion sections [56, 57] are not satisfying, the reported procedure when reading an article is of concern especially because of the high rate of respondents who read the abstract and the discussion but do not read the methods. Though the implementation of structured abstracts has improved their quality [58] the possibility to improve their accuracy seems limited especially in smaller journals [59]. Therefore it should be emphasised that the role of an abstract is to inform the reader of the potential interest of an article [60] and that it can not substitute the critical appraisal of the whole article, especially with regard to decisions involving patients.

Critical appraisal and knowledge of technical terms. The low rate of respondents who read the methods section corresponds with their inadequate methods of appraising the scientific validity of research articles. The responses to this question are comparable to a previous study [23]. Experience and discussions with colleagues are necessary when reading journal articles but they can only complement a critical appraisal of the methods section to validate the scientific sound- 
ness of an article. Such an appraisal is necessary because the proportion of inadequate methods in clinical research is still noteworthy $[61,62]$ and also for assessing the applicability of results to daily clinical practice. Such behaviour could be due to lack of time but the knowledge of technical terms suggests that it is also related to problems with the adequate appraisal of methods sections. Though the knowledge of technical terms of respondents seems better than that of general practitioners [27] it is not satisfying and their lack of knowledge of widely used terms (e.g. confidence intervals, odds ratios) is remarkable. The readiness to learn however, is encouraging and should guide further efforts for continuing medical education in the field of biostatistics and critical appraisal. But the relatively high proportion of respondents who attached little value to these technical terms in clinical practice suggests that such efforts should be incorporated in routine CME events rather than in the promotion of lectures or workshops especially dedicated to evidence-based medicine or critical appraisal.

Importance of journals. The importance of journals in continuing medical education was emphasized by the fact that $90 \%$ of respondents valued them as important for prescribing new drugs. Only a minority however, reported that they could rely solely on them when prescribing a new drug for the first time. These findings are in line with responses to other questions in this survey (Fig. 2, Table 3 ). Furthermore they correspond with studies about changing behaviour and diffusion of new drugs and show that journals can play an important role but are only part of a complex network of factors which influence the prescription of innovative drugs $[1,63,64,65]$.

Conclusions. This survey showed that self-reported reading efforts and critical appraisal skills of diabetologists are slightly higher compared with non-specialists. The results also suggest that important parts of the evidence-based medicine concept are still not incorporated in clinical practice. Since it is reasonable to presume that the integration of external evidence in clinical decision making is essential for better health care [66, 67] and this concept has been promoted widely in medical journals and special CME events, future efforts should be made to better incorporate evidence-based medicine concepts in general CME events, graduate, and undergraduate medical education.

Acknowledgements. I am indebted to R. Kollek for the supervision of this work and the willingness to support my dissertation. I am also grateful to $\mathrm{C}$. de Wit, C. Trelle, and the anonymous reviewers for their constructive comments on previous versions of this paper.

\section{Appendix}

Because of limited space the questions are not presented in the original layout (Fig. 2). 
1. Please estimate the influence of the various factors quoted below on your therapeutic decision making (Therapy of diabetes):

$\begin{array}{cccccc}\begin{array}{c}\text { very } \\ \text { strong }\end{array} & \text { strong } & \begin{array}{c}\text { rather } \\ \text { strong }\end{array} & \begin{array}{c}\text { rather } \\ \text { minor }\end{array} & \begin{array}{c}\text { no } \\ \text { minor }\end{array} & \begin{array}{c}\text { do not } \\ \text { influence }\end{array} \\ 5 & 4 & 3 & 2 & 1 & 0\end{array}$

1. Medical study (university education)

2. Books; 3. Published trials in journals; 4. Reviews in journals; 5 . Systematic reviews/metaanalyses in journals; 6 . Advertisements in journals; 7. Technical literature from the pharmaceutical industry; 8. Published guidelines; 9. Guidelines/standards of the own hospital; 10. CME events; 11. Quality circles; 12. Own clinical experience; 13. Colleagues; 14. Sales representatives of the pharmaceutical industry; 15. Wishes and desires from patients

2. By which of these factors quoted above do you hear of a new drug for the first time (not more than three numbers)?

1:

2:

3:

3. Do you use databases regularly?

$\square$ Yes

$\square$ No

If yes: 1 . How often? per month

2. How much time does it usually take? min.

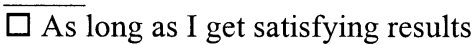

If no: 1 . The effort is to big.

$\square$ Yes $\square$ No

2. I do not know databases.

$\square$ Yes $\square$ No

3. The results, which I could get, are not satisfying.

$\square$ Yes $\square$ No

4. Other reasons.

(free text)

4. Where is your nearest internet access or MEDLINE/EMBASE search possibility located?

$\square$ Own ward/surgery

$\square$ Library in the own hospital

$\square$ University library/other hospital library

$\square$ At home

5. How much time do you spend for reading technical literature?

Journals: hours/week

Books: hours/week

6. Which journals do you read regularly?

$\square$ Arzneimitteltelegramm $\square$ Internist $\square$ Dtsch Med Wochenschr $\square$ Medical Tribune $\square$ Münch Med Wochenschr $\square$ N Engl J Med Stoffwechsel $\square$ Exp Clin Endocrinol Diabetes $\square$ others (free text)

$\square$ Deutsches Ärzteblatt

$\square$ Diabetes und

7. Which part of an article do you usually read?

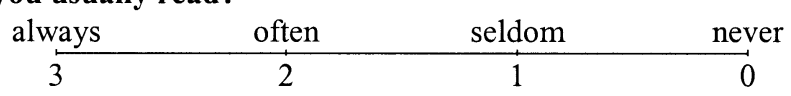

1. Title

2. Abstract; 3. Introduction; 4. Methods; 5. Results; 6. Discussion

Fig. 2 . 
8. When you read a research article related to a clinical problem, how do you evaluate its scientific validity?

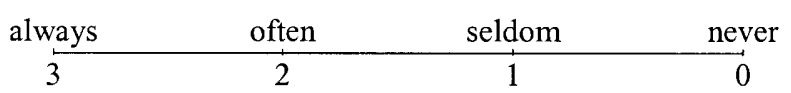

1. Compare with own

experience

2. Rely on the editors/peer reviewer process; 3. Depending on the authors; 4 . Contact the authors;

5. Examine methods and statistics; 6. Discussion with colleagues; 7. Discussion with clinical experts (e.g. from a university hospital); 8. Discussion with methodological experts (e.g. a statistician)

9. Please indicate your position to the following terms:

$$
\begin{array}{ccc}
\text { do not know knowledge } & \text { understand and } \\
\text { but would like } & \text { but no } & \text { some could explain } \\
\text { do not know to understand understanding understanding } & \text { to others }
\end{array}
$$

1. Systematic review

2. Meta-analysis; 3. Publication bias; 4. Relative risk reduction (RRR); 5. Absolute risk reduction (ARR); 6. Number needed to treat (NNT); 7. Intention-to-treat analysis; 8. McNemar-QualityScale; 9. Confidence interval; 10. Alpha-error/Type-I-error; 11. Beta-error/Type-II-error; 12. Positive predictive value; 13 . Odds ratio

10. How important is the handling of these terms for your daily clinical practice? very important rather important rather unimportant not important

320110

11. Do you think the information provided in scientific journals is sufficient enough for prescribing new drugs?

$\square$ Yes $\quad \square$ No

12. How important are scientific journals for prescribing a new drug for the first time?

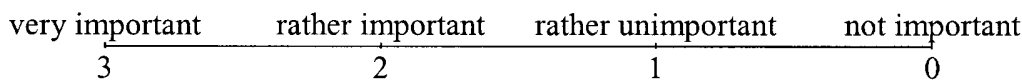

\section{Personal data:}

Categories: Year of graduation; Sex; Speciality; Work place; Location of the work place; weekly hours of work; proportion of diabetic patients

14. How comprehensible was this questionnaire?

\begin{tabular}{cccc} 
difficult & rather difficult & rather easy & easy \\
\hline 4 & 3 & 2 & 1 \\
$\square$ & $\square$ & $\square$ & $\square$
\end{tabular}

15. We would appreciate any comments from you:

Response category: (free text) 


\section{References}

1. Haug JD (1997) Physicians' preferences for information sources: a meta-analytic study. Bull Med Libr Assoc 85:223-232

2. Gerlach FM, Beyer M (1999) Continuing medical education from the view of ambulatory care physicians - representative outcomes and needs in Bremen and SaxonyAnhalt (Ärztliche Fortbildung aus der Sicht niedergelassener Ärztinnen und Ärzte: Repräsentative Ergebnisse aus Bremen und Sachsen-Anhalt). Z Ärztl Fortbild Qualitätssich 93:581-590

3. Frank E, Baldwin G, Langlieb AM (2000) Continuing medical education habits of US women physicians. J Am Med Womens Assoc 55:27-28

4. Robert G, Gabbay J, Stevens A (1998) Which are the best information sources for identifying emerging health care technologies. Int J Technol Assess Health Care 14:636643

5. Cohen SJ, Weinberger M, Hui SL, Tierney WM, McDonald CJ (1985) The impact of reading on physicians' nonadherence to recommended standards of medical care. Soc Sci Med 21:909-914

6. Bergman DA, Patell RH (1986) The impact of reading a clinical study on treatment decisions of physicians and residents. J Med Educ 61:380-386

7. Lamas GA (1992) Do the results of randomized clinical trials of cardiovascular drugs influence medical practice? N Engl J Med 327:241-247

8. Ketley D, Woods KL (1993) Impact of clinical trials on clinical practice: example of thrombolysis for acute myocardial infarction. Lancet 342:891-894

9. Baxter C, Jones R, Corr L (1998) Time trend analysis and variations in prescribing lipid lowering drugs in general practice. BMJ 317:1134-1135

10. Mamdani MM, Tu JV (2001) Did the major clinical trials of statins affect prescribing behaviour? CMAJ 164:16951696

11. Riis P (2000) Obligatory information on patient-oriented end point outcome. Diabetologia 43:135-136

12. Wulff HR, Andersen B, Brandehoff P, Guttler F (1987) What do doctors know about statistics? Stat Med 6:3-10

13. Forrow L, Taylor WC, Arnold RM (1992) Absolutely relative: how research results are summarized can affect treatment decisions. Am J Med 92:121-124

14. Naylor CD, Chen E, Strauss B (1992) Measured enthusiasm: does the method of reporting trial results alter perceptions of therapeutic effectiveness? Ann Intern Med 117: 916-921

15. Cranney M, Walley T (1996) Same information different decisions: the influence of evidence on the management of hypertension in the elderly. Br J Gen Pract 46:661-663

16. Fairhurst K, Huby G (1998) From trial to practical knowledge: qualitative study of how general practitioners have accessed and used evidence about statin drugs in their management of hypercholesterolaemia. BMJ 317:1130-1134

17. Berger M, Richter B, Mühlhauser J (1997) Evidence-based medicine. Medicine based on rational principles (Evidencebased Medicine: Eine Medizin auf rationaler Grundlage). Internist (Berl) 38:344-351

18. Raspe H (2000) Möglichkeiten und Gefährdungen der evidenzbasierten Medizin in Deutschland. In: Kunz R, Ollenschläger G, Raspe H, Jonitz G, Kolkmann F-W (eds) Lehrbuch Evidenzbasierte Medizin in Klinik und Praxis. Deutscher Ärzte-Verlag, Köln, pp 50-61

19. Phillips PA, Kelly S, Best J (1999) Implementing and sustaining evidence-based clinical practice in Australia: the Evidence Based Clinical Practice Research Initiative. J Eval Clin Pract 5:163-168

20. Sachverständigenrat für die Konzertierte Aktion im Gesundheitswesen (2001) Bedarfsgerechtigkeit und Wirtschaftlichkeit: Band II Qualitätsentwicklung in Medizin und Pflege. Sachvertändigenrat für die Konzertierte Aktion im Gesundheitswessen, Bonn

21. Stross JK, Harlan WR (1979) The dissemination of new medical information. JAMA 241:2622-2624

22. Stinson ER, Mueller DA (1980) Survey of health professionals' information habits and needs. Conducted through personal interviews. JAMA 243:140-143

23. Williamson JW, Pearl SG, Weiss R, Skinner EA, Bowes F (1989) Health science information management and continuing education of physicians: a survey of US primary care practitioners and their opinion leaders. Ann Intern Med 110:151-160

24. Ollenschläger G, Thust W, Pfeiffer A, Engelbrecht J, Birker T, Ratschko KW (1995) Participation in continuing education by German physicians - exemplified by the Schleswig-Holstein study (Das Fortbildungsverhalten der deutschen Ärzteschaft - dargestellt am Beispiel der Schleswig-Holstein-Studie). Z Ärztl Fortbild (Jena) 89:7580

25. Hunt RE, Newman RG (1997) Medical knowledge overload: a disturbing trend for physicians. Health Care Manage Rev 22:70-75

26. Johnson KH, Dayrit M, Bazargan M (1997) The reading habits of family practice residents. Fam Med 29:488491

27. McColl A, Smith H, White P, Field J (1998) General practitioners' perceptions of the route to evidence based medicine: a questionnaire survey. BMJ 316:361-365

28. Saint S, Christakis DA, Saha S et al. (2000) Journal reading habits of internists. J Gen Intern Med 15:881-884

29. Deibler G (1995) Fortbildungsverhalten niedergelassener Internisten im Raum Südwürttemberg (dissertation). Eberhard-Karls Universität Tübingen, Tübingen

30. Asch DA, Jedrziewski MK, Christakis NA (1997) Response rates to mail surveys published in medical journals. J Clin Epidemiol 50:1129-1136

31. Cummings SM, Savitz LA, Konrad TR (2001) Reported response rates to mailed physician questionnaires. Health Serv Res 35:1347-1355

32. Ajzen I (1988) Attitudes, personality and behavior. Open University Press, Milton Keynes

33. Alreck PL, Settle RB (1995) The survey research handbook. 2nd ed. Irwin/McGraw-Hill, Boston

34. Avorn J, Chen M, Hartley R (1982) Scientific versus commercial sources of influence on the prescribing behaviour of physicians. Am J Med 73:4-8

35. Curry L, Purkis IE (1986) Validity of self-reports of behavior changes by participants after a CME course. J Med Educ 61:579-584

36. Saver BG, Taylor TR, Treadwell JR, Cole WG (1997) Do physicians do as they say? The case of mammography. Arch Fam Med 6:543-546

37. Adams AS, Soumerai SB, Lomas J, Ross-Degnan D (1999) Evidence of self-report bias in assessing adherence to guidelines. Int J Qual Health Care 11:187-192

38. Bradley CP (1991) Decision making and prescribing patterns - a literature review. Fam Pract 8:276-287

39. Wazana A (2000) Physicians and the pharmaceutical industry. JAMA 283:373-380

40. Braddock CH, Edwards KA, Hasenberg NM, Laidley TL, Levinson W (1999) Informed decision making in outpatient practice. JAMA 282:2313-2320 
41. Beauchamp TL, Childress JF (1994) Principles of biomedical ethics. 4th ed. Oxford University Press, New York

42. Golin CE, DiMatteo MR, Gelberg L (1996) The role of patient participation in the doctor visit. Diabetes Care 19:1153-1164

43. Barry MJ (1999) Involving patients in medical decisions [Editorial]. JAMA 282:2356-2357

44. Berger M, Mühlhauser I (1999) Diabetes care and patientoriented outcomes. JAMA 281:1676-1678

45. Lutfey KE, Wishner WJ (1999) Beyond "compliance" is "adherence". Diabetes Care 22:635-639

46. Chimoskey SJ, Norris TE (1999) Use of MEDLINE by rural physicians in Washington State. J Am Med Inform Assoc 6:332-333

47. Smith R (1996) What clinical information do doctors need? BMJ 313:1062-1068

48. Gorman PN, Ash J, Wykoff L (1994) Can primary care physicians' questions be answered using the medical journal literature. Bull Med Libr Assoc 82:140-146

49. Jerome RN, Giuse NB, Gish KW, Sathe NA, Dietrich MS (2001) Information needs of clinical teams: analysis of questions received by the Clinical Informatics Consult Service. Bull Med Libr Assoc 89:177-184

50. Mouillet E (1999) Language barriers and bibliographic retrieval effectiveness: use of MEDLINE by French-speaking end users. Bull Med Libr Assoc 87:451-455

51. McAlister FA, Graham I, Karr GW, Laupacis A (1999) Evidence-based medicine and the practicing clinician. J Gen Intern Med 14:236-242

52. Egger M, Zellweger T, Antes G (1996) Randomised trials in German-language journals. Lancet 347:1047-1048

53. Navarro FA (1996) English or German? The language of medicine based on the bibliographic data appearing in the Deutsche Medizinische Wochenschrift (1920 to 1995). [Englisch oder Deutsch? Die Sprache der Medizin aufgrund der in der Deutschen Medizinischen Wochenschrift erschienenen Literaturangaben (1920 bis 1995)]. Dtsch Med Wochenschr 121:1561-1566

54. Pitkin RM, Branagan MA, Burmeister LF (1999) Accuracy of data in abstracts of published research articles. JAMA 281:1110-1111
55. Froom P, Froom J (1993) Deficiencies in structured medical abstracts. J Clin Epidemiol 46:591-594

56. Gøtzsche PC (1989) Methodology and overt and hidden bias in reports of 196 double-blind trials of nonsteroidal antiinflammatory drugs in rheumatoid arthritis. Control Clin Trials 10:31-56

57. Olsen O, Middleton P, Ezzo J et al. (2001) Quality of Cochrane reviews: assessment of sample from 1998. BMJ 323:829-832

58. Taddio A, Pain T, Fassos FF, Boon H, Ilersich AL, Einarson TR (1994) Quality of nonstructured and structured abstracts of original research articles in the British Medical Journal, the Canadian Medical Association Journal and the Journal of the American Medical Association. CMAJ 1994:1611-1615

59. Pitkin RM, Branagan MA (1998) Can the accuracy of abstracts be improved by providing specific instructions? JAMA 280:267-269

60. Fletcher RH, Fletcher SW, Wagner EH (1996) Clinical epidemiology. The essentials. 3rd edn. Williams \& Wilkins, Baltimore

61. Altman DG (1994) The scandal of poor medical research. BMJ 308:283-284

62. Altman DG (2000) Statistics in medical journals: some recent trends. Stat Med 19:3275-3289

63. Rogers EM (1995) Diffusion of innovations. 4th ed. The Free Press, New York

64. Armstrong D, Reyburn H, Jones R (1996) A study of general practitioners' reasons for changing their prescribing behaviour. BMJ 312:949-952

65. Allery LA, Owen PA, Robling MR (1997) Why general practitioners and consultants change their clinical practice: a critical incident study. BMJ 314:870-874

66. Vijan S, Kent DM, Hayward RA (2000) Are randomized controlled trials sufficient evidence to guide clinical practice in Type II (non-insulin-dependent) diabetes mellitus? Diabetologia 43:125-130

67. Richter B, Berger M (2000) Randomized controlled trials remain fundamental to clinical decision making in Type II diabetes mellitus: a comment to the debate on randomized controlled trials. Diabetologia 43:254-258 